\title{
Cryptorchidism and Testicular
} Tumor: Comprehensive Analysis of Common Clinical Features and Search of SNVs in the KIT and AR Genes

\section{OPEN ACCESS}

Edited by:

Isabel R. Schlaepfer,

School of Medicine, University of Colorado, United States

Reviewed by: Erika Di Zazzo,

University of Molise, Italy Caterina Squillacioti,

University of Naples Federico II, Italy

*Correspondence:

Rosa María Vigueras-Villaseñor rmvigueras@yahoo.com.mx Margarita Dolores Chávez-Saldaña mdoloreschs@gmail.com

Specialty section:

This article was submitted to Molecular and Cellular Oncology,

a section of the journal

Frontiers in Cell and Developmental

Biology

Received: 28 April 2020

Accepted: 21 July 2020

Published: 07 August 2020

Citation:

Landero-Huerta DA,

Vigueras-Villaseñor RM,

Yokoyama-Rebollar E,

García-Andrade F

Rojas-Castañeda JC,

Herrera-Montalvo LA, Díaz-Chávez J,

Pérez-Añorve IX,

Aréchaga-Ocampo $E$ and

Chávez-Saldaña MD (2020)

Cryptorchidism and Testicular Tumor: Comprehensive Analysis of Common Clinical Features and Search of SNVs

in the KIT and AR Genes.

Front. Cell Dev. Biol. 8:762.

doi: 10.3389/fcell.2020.00762
Daniel Adrian Landero-Huerta ${ }^{1,2}$, Rosa María Vigueras-Villaseñor ${ }^{1 *}$, Emiy Yokoyama-Rebollar ${ }^{3}$, Fabiola García-Andrade ${ }^{1}$, Julio César Rojas-Castañeda ${ }^{1}$, Luis Alonso Herrera-Montalvo ${ }^{4,5}$, José Díaz-Chávez 6 , Isidro Xavier Pérez-Añorve², Elena Aréchaga-Ocampo ${ }^{7}$ and Margarita Dolores Chávez-Saldaña ${ }^{1 *}$

\begin{abstract}
'Laboratorio de Biología de la Reproducción, Instituto Nacional de Pediatría, Mexico City, Mexico, ${ }^{2}$ Posgrado en Ciencias Naturales e Ingeniería, Unidad Cuajimalpa, Universidad Autónoma Metropolitana, Mexico City, Mexico, ${ }^{3}$ Departamento de Genética Humana, Instituto Nacional de Pediatría, Mexico City, Mexico, ${ }^{4}$ Unidad de Investigación Biomédica en Cáncer, Instituto Nacional de Cancerología-Instituto de Investigaciones Biomédicas, Universidad Nacional Autónoma de México, Mexico City, Mexico, ${ }^{5}$ Instituto Nacional de Medicina Genómica, Mexico City, Mexico, ${ }^{6}$ Instituto Nacional de Cancerología, Mexico City, Mexico, ${ }^{7}$ Departamento de Ciencias Naturales, Unidad Cuajimalpa, Universidad Autónoma Metropolitana, Mexico City, Mexico
\end{abstract}

Allelic variants in genes implicated in the development of testicular germ cell tumor (TGCT) could be present in patients with cryptorchidism (CO). Currently; the mechanisms explaining this relationship are still unknown. In this study the common clinical features in patients with CO and TGCT and 6 variants of KIT and AR genes associated to TGCT were analyzed. Population analyzed included 328 individuals: 91 patients with CO; 79 with TGCT, 13 of them with previous CO diagnosis, and 158 healthy males. Of the 13 patients with TGCT and history of CO, one patient $(7.7 \%)$ presented the heterozygous form of the variant rs121913507 and two patients (15.4\%) presented homozygote genotype for the variant rs121913506 in KIT gene. Interestingly, the heterozygous form for the variant rs121913506 of KIT gene was identifying in all of 13 patients. The rs201934623, rs774171864, and rs12014709 variants of the $A R$ gene did not show any clinical association. Our results strongly support that genetic component in CO could be conditioning for the development of TGCT. Notably, KIT gene variants might be determinants in the pathological association between TGCT and $\mathrm{CO}$.

Keywords: SNVs, $K I T, A R$, isolated cryptorchidism, testicular germ cell tumor

\section{INTRODUCTION}

Cryptorchidism (CO) or undescended testis (OMIM\#219050), is the most common genitourinary malformation in newborn males. Many reports indicate that boys with $\mathrm{CO}$ have an overall relative risk (RR) of 4.8 (95\% confidence interval 4.0-5.7) of develop testicular germ cell tumors (TGCT, OMIM\#273300; Dieckmann and Pichlmeier, 2004; Kratz et al., 2010), which is the most frequent solid tumor in men between 15 and 44 years of age. TGCT is classified generally as seminoma 
(sTGCT) and non-seminoma (nsTGCT; Kratz et al., 2010). Although the association of CO and TGCT has been clinically established, the mechanisms leading to carcinogenesis are still unknown (Ferguson and Agoulnik, 2013). Due to the presence of common genetic factors in the etiology of both pathologies, it is possible infer the existence of a molecular genetic relationship between $\mathrm{CO}$ and the development of TGCT (Vigueras-Villaseñor et al., 2015).

Studies that have been focused on searching diagnostic markers for TGCT proposed several single nucleotide variants (SNVs) in genes such as POU5F1, DND1, KIT, KITLG, AR, DMTR1, SPRY4, BCL2, NANOG, TGFBR2, PTEN, AKT1, PDE11A, GATA4, and THOC1 (Dalgaard et al., 2011; Turnbull and Rahman, 2011; Landero-Huerta et al., 2017; Litchfield et al., 2017). Proto-oncogene tyrosine kinase receptor (KIT) and the androgen receptor $(A R)$ are relevant in the development of TGCT. Although it has not been shown that genetic variants in these genes are responsible for causing $\mathrm{CO}$ or Germ cell neoplasia in situ (GCNIS) a precursor lesion to TGCT, both genes have a role in testicle development and testicular carcinogenic process, influencing directly as in the case of $A R$, through nongenomic pathways (Walker, 2003). The KIT gene codifies a class III homodimeric receptor with tyrosine kinase activity in humans. KIT is activates by its ligand KITLG codified by the KITLG gene (Agarwal et al., 2014). Both, receptor and ligand are essential for survival, migration and differentiation of the early germ cells (gonocytes; Sheikine et al., 2012). Currently, gonocytes have been proposed as responsible for the development of GCNIS (Vigueras-Villaseñor et al., 2015; Berney et al., 2016). On the other hand, the $A R$ gene produces a homodimeric cytosolic nuclear receptor, which binds to androgens and induces gene transcription ( $\mathrm{Li}$ and Al-Azzawi, 2009; Davis-Dao et al., 2011). AR is essential in the inguinal-scrotal phase of testicular descent during the male fetal stage by controlling the normal gonocyte proliferation in the testis (Merlet et al., 2007; Hutson et al., 2015). Interestingly, AR is overexpressed in GCNIS and it has been found in gonocytes unable to differentiate properly (Merlet et al., 2007).

Although several studies clearly show a high risk of develop testicular neoplasia in patients with $\mathrm{CO}$, there are no studies that correlate SNVs in patients with TGCT and CO. Therefore, the aims of this study were to analyze the relevant common clinical features in Mexican patients with isolated CO and TGCT, and to identify SNVs in the KIT and $A R$ genes by allelic discrimination in patients with TGCT and history of CO. This study reports clinical features and genetic variant that may support the early diagnosis of TGCT in pediatric patients with isolated CO.

\section{MATERIALS AND METHODS}

\section{Subjects}

The study included 328 individuals referred to the Urology Service of the National Institute of Pediatrics and National Institute of Cancerology in Mexico, from 2006 to 2017. The patients were divided in two groups as follows: the first group consisted in 91 patients with confirmed diagnosis of isolated or non-syndromic $\mathrm{CO}$; the second group included 79 patients with confirmed diagnosis of TGCT, 66 of them without history of CO, and 13 patients with confirmed history of isolated CO. In all patients the diagnosis were validated by clinical history, physical examination and imaging studies in all cases. Subsequently, clinical data was obtained and patients were classified according to clinical features. In addition, 158 healthy men without history of CO or TGCT were included as a control group.

All patients and healthy men were Mexican descent, at least two generations, with 46, XY normal karyotype. This study is part of the project with registration number INP-01/2016, approved by the Research and Ethic Committee of INP and all patients included in the study had previously signed the informed consent.

\section{Genotyping of Allelic Variants}

DNA was obtained from peripheral blood sample from patients with CO, patients with TGCT without history of CO and healthy individuals according to standard protocols QIA-AMP DNA blood mini kit, [Qiagen, Vienna, Austria]. DNA from patients with both conditions (TGCT and history of CO) was obtained from the testicular tumor samples embedded in paraffin a according to the manufacturer's protocol FFPE RNA/DNA Purification Plus Kit, [Norgen Biotec Corp, Ontario, Canada]. Subsequently, DNA samples were used for genotyping analysis of rs121913507 (D816V), rs121913506 (D816H), and rs121913514 (N822K) SNVs in the KIT gene and rs201934623 (P392S), rs774171864 (A299T), and rs12014709 (g.67718624T > G) SNVs in the AR gene. The genotyping was performed through allelic discrimination according to established protocol of TaqMan [BMG chemistry Applied Biosystems, Foster City, CA, United States]. The genotyping rate was $99.9 \%$ and $30 \%$ of the randomized samples, which showed $100 \%$ reproducibility in duplicate trials for the 6 SNVs.

\section{Statistical Analysis}

The comparison between the genotypes obtained and the clinical data was performed using SPSS v21 statistical package. Chisquare test or Fisher's exact test were used for the SNVs analysis in different groups; in all cases, the $P$ value $<0.05$ was considered significant. The statistical power was calculated from the frequency of the minor allele of the variants with a significant $P$ value due to the small number of individuals included in this study. Finally, the allelic frequencies of the SNVs in the population were compared with the frequencies reported in other populations in the HapMap and in the project of the 1000 genomes of European Ancestry (EUR), African Ancestry (AFR), East Asian Ancestry (EAS), South Asian Ancestry (SAS), Latino Ancestry (AMR), and Mexican Ancestry in Los Angeles (MXL).

\section{Analysis of Linkage Disequilibrium and Haplotypes}

Haplotype association analysis was performed with the variants located in the same gene. Those variants with a $D^{\prime}$ value equal or greater than 0.8 were considered in linkage disequilibrium (LD) and haplotypes formed by our cases and controls were 
compared using Haploview 4.2 software (Barrett et al., 2004), and then correlating only the patients with bilateral and unilateral CO phenotypes. The epistasis between variants located in different loci were assayed by a Multifactor Dimensionality Reduction (MDR) method in the MDR 3.0.2 software (Moore et al., 2006), since all $P$ values were greater than 0.05 and Cross Validation (CV) values equal to $10 / 10$, were considered.

\section{Analysis of Population Structure}

The analysis of rs121913506 (D816H), rs121913514, rs774171864, and rs12014709 SNVs in 328 individuals were performed. The software STRUCTURE 2.3.4. (Pritchard Lab, Stanford University) was used to test the stratification within the samples. A mixing model consisting of a burning period of $1,000,000$ and $1,000,000$ repetitions with a $k=2$ was used. It should be noted that, although the ancestry informative markers (AIMS) analysis was not performed, the SNVs allowed us to evidence the structural phenomenon of our population. The value of $\delta>1$ indicated that majority of the analyzed individuals were mixed (Rosenberg, 2002).

\section{RESULTS}

\section{Clinical Features Associated to $\mathrm{CO}$ and TGCT}

At the time of diagnosis, the patients with CO $(n=91)$ had an average age of $3.5 \pm 0.3$ years, and those with TGCT had $26.5 \pm 0.9$ years [TGCT with CO $(n=13)=24.3 \pm 2.5$ years, and TGCT without CO $(n=66)=26.9 \pm 1.0$ years].

In patients with $\mathrm{CO}$, the frequency of bilateral $\mathrm{CO}$ was $48.3 \%$ (44/91); all patients with CO underwent orchidopexy, but $73.6 \%$ (68/91) underwent orchidopexy after 18 months of age (2-16 years; data not shown), and only $16.5 \%(15 / 91)$ required orchiectomy due to the presence of testicular atrophy (Table 1). In addition, 13.2\% (12/91) of the patients reported family history of CO and only $2.2 \%$ (2/91) reported family history of TGCT (Table 1).

In the group of TGCT patients, $16.5 \%$ (13/79) had CO, of them, $38.5 \%(5 / 13)$ underwent orchidopexy in an average of 8.8 years of age. All patients of the TGCT group (79/79) underwent orchiectomy at TGCT diagnosis. The most frequent histological type of TGCT patients was nsTGCT [61\% (48/79)]. The subgroup of 13 patients with TGCT and CO did not report family history of CO or TGCT, while in the subgroup of TGCT without CO, only $4.5 \%$ (3/66) patients had family history of TGCT (Table 1).

\section{Genotyping}

In order to identify a genetic marker associated to $\mathrm{CO}$ condition or to genetic susceptibility to develop TGCT in patients with CO, 6 SNVs were analyzed in this study. Three SNVs in the KIT gene, including rs121913507 (D816V), rs121913506 (D816H), and rs121913514 (N822K) were evaluated. While the 3 SNVs analyzed in the AR gene were rs201934623 (P392S), rs774171864 (A299T), and rs12014709 (c.66718624 T/G). Initially the subgroups of patients with TGCT and history of CO $(n=13)$ were compared with those patients with TGCT without CO $(n=66)$. Posteriorly, we compared the subgroup of TGCT and CO patients with isolated CO patients $(n=91)$, and finally, with healthy controls ( $n=158$; Table 2). Results showed that the variant rs121913507 (D816V) of the KIT gene was found in 1/13 (7.7\%) of patients with TGCT and $\mathrm{CO}$ in a heterozygous form, while the rest of patients [12/13 (92.3\%)] presented a homozygote genotype (AA). The comparison among the rest of the patients and healthy controls did not show significant statistically differences [TGCT + CO vs TGCT $(P=0.162)$, TGCT + CO vs CO $(P=0.125)$, and TGCT + CO vs Controls $(P=0.076)$, respectively]. The variant $\mathrm{rs} 121913506(\mathrm{D} 816 \mathrm{H})$ of the KIT gene was found in heterozygous form in 11/13 (84.6\%) patients with TGCT and CO, while 2/13 (15.4\%) patients with TGCT and CO had a homozygote genotype (CC). In contrast to the variant rs121913507 (D816V), the comparison between the variant rs121913506 $(\mathrm{D} 816 \mathrm{H})$ of patients with TGCT and CO with the rest of the patients and healthy controls showed statistically significant differences [TGCT + CO vs TGCT $(P=0.025)$, TGCT + CO vs CO $(P=0.015)$, and TGCT + CO vs Controls

TABLE 1 | Clinical features of the patients.

\begin{tabular}{|c|c|c|c|c|}
\hline \multirow[t]{2}{*}{ Clinical features } & & \multirow{2}{*}{$\begin{array}{c}\text { Patients with } \\
\text { isolated CO } \\
n=91(\%)\end{array}$} & \multicolumn{2}{|c|}{ Patients with TGCT $n=79$} \\
\hline & & & $\begin{array}{c}\text { TGCT with CO } \\
n=13(\%)\end{array}$ & $\begin{array}{l}\text { TGCT without } \\
\text { CO } n=66(\%)\end{array}$ \\
\hline \multicolumn{2}{|l|}{ Age at diagnosis } & $3.5 \pm 0.3$ & $24.3 \pm 2.5$ & $26.9 \pm 1.0$ \\
\hline \multirow[t]{3}{*}{$\mathrm{CO}$} & Bilateral & 44 (48.3) & 7 (53.8) & NA \\
\hline & Left & $25(27.5)$ & $3(23.1)$ & \\
\hline & Right & $22(24.2)$ & $3(23.1)$ & \\
\hline \multirow[t]{2}{*}{ Orchidopexy } & Yes & $91(100)$ & $5(38.5)$ & NA \\
\hline & No & $0(0)$ & $8(61.5)$ & \\
\hline \multirow[t]{2}{*}{ Orchiectomy } & Yes & $15(16.5)$ & $13(100)$ & $66(100)$ \\
\hline & No & $76(83.5)$ & $0(0)$ & $0(0)$ \\
\hline \multirow{2}{*}{$\begin{array}{l}\text { Family history of } \\
\mathrm{CO}\end{array}$} & Positive & $12(13.2)$ & $0(0)$ & $0(0)$ \\
\hline & Negative & $79(86.8)$ & $13(100)$ & $66(100)$ \\
\hline \multirow{2}{*}{$\begin{array}{l}\text { Family history of } \\
\text { TGCT }\end{array}$} & Positive & $2(2.2)$ & $0(0)$ & $3(4.5)$ \\
\hline & Negative & $89(97.8)$ & $13(100)$ & $63(95.5)$ \\
\hline \multirow[t]{3}{*}{ TGCT } & Bilateral & NA & $1(7.7)$ & $0(0)$ \\
\hline & Left & & $4(30.8)$ & $36(54.5)$ \\
\hline & Right & & $8(61.5)$ & $30(45.5)$ \\
\hline \multirow{4}{*}{$\begin{array}{l}\text { Clinical stage at } \\
\text { diagnosis }\end{array}$} & I & NA & 4 (30.8) & $33(50)$ \\
\hline & $\|$ & & 7 (53.8) & $15(21.7)$ \\
\hline & III & & $1(7.7)$ & 12 (18.2) \\
\hline & IV & & $1(7.7)$ & $6(9.1)$ \\
\hline \multirow[t]{2}{*}{ Metastasis } & Positive & NA & 7 (53.8) & $24(36.4)$ \\
\hline & Negative & & $6(46.2)$ & 42 (63.6) \\
\hline \multirow{2}{*}{$\begin{array}{l}\text { Tumor histological } \\
\text { type }\end{array}$} & nsTGCT & NA & 10 (76.9) & 38 (57.6) \\
\hline & sTGCT & & $3(23.1)$ & $28(42.4)$ \\
\hline
\end{tabular}

$\overline{\text { nsTGCT, Non-Seminomatous Testicular Germ Cells Tumor; sTGCT, Seminomatous }}$ Testicular Germ Cells Tumor; and NA, Not Apply. 
( $P=0.005)$, respectively]. The analysis of the rs121913514 (N822K) variant of the KIT gene between all groups did not show any differences (Table 2).

The results of the analysis of the SNVs in the AR gene showed that the rs12014709 (g.67718624T > G) variant located in the intronic region of gene presented different genotypes, however, no statistically significant differences resulted between the groups (Table 2). The variants rs201934623 (P392S) and rs774171864 (A299T) of the $A R$ gene did not show any differences.

\section{TGCT With History of CO Patients and the KIT Gene}

Considering that the group of patients with TGCT and CO showed significant differences in the genotypes of the KIT gene, we analyzed their association with significant clinical features (Table 3). In the first analysis, the patients 2 and 3 that presented the variant rs121913506 (D816H) in homozygous form, were young and suffered unilateral CO (although in opposite side), however, both presented different tumor histological type and only one of them developed metastasis. By the other hand, the patient 13 presented the variant rs121913507 (D816V) in heterozygous form, he had history of bilateral CO and TGCT was unilateral, the tumor type was nsTGCT and he did not develop metastasis.

Interestingly, higher frequency of metastasis was observed in patients with TGCT and previous $\mathrm{CO}(n=13)$ compared to those who presented only TGCT without history of CO $(n=66)$ [53.8\% (7/13) vs 36.4\% (24/66)] and histological type of nsTGCT [76.9\% (10/13) vs 57.6\% (38/66)] (Table 1). Furthermore, only $38.5 \%(5 / 13)$ of patients with TGCT and previous CO underwent orchidopexy in an age average of 8.8 years, while the rest [8/13
(61.5\%)] of these patients did not have orchidopexy. The nsTGCT histological type $[87.5 \%(7 / 8)$ vs $60 \%(3 / 5)]$, metastasis $[75 \%$ $(6 / 8)$ vs $20 \%(1 / 5)]$, and more advanced tumor stage were most frequently presented in these 8 patients that did not underwent orchidopexy (Table 3).

\section{Allelic Frequencies}

The allelic frequencies for the 3 variants of the KIT gene and 3 variants of the $A R$ gene analyzed in this study were search in the literature and in different worldwide databases for general population, to compare these information to the allelic frequencies observed in our results. Only the variants rs121913507, rs201934623, rs774171864, and rs12014709 coincided with the reported frequencies (Table 4).

Haplotype blocks conformed by variants located in the same gene were not identify. In the same way, MDR analysis did not show any significant statistical gene-gene interaction. However, the analysis of the population structure of the 4 of the 6 SNVs, a value of $\delta=2.27$ was identified.

\section{DISCUSSION}

Despite the high rate of spontaneous descent during the first year of life, $\mathrm{CO}$ is still one of the most common congenital malformations among males worldwide, with a frequency of 1$3 \%$; and is one of the risk factors for development TGCT (Banks et al., 2013). Besides, TGCT is the most common cancer in young men between 15 to 44 years (Trabert et al., 2014), with an ageadjusted rate of 11.1 per 100,000 men (world standard). Among the solid tumors with higher mortality, TGCT are found in the

TABLE 2 | Genotypic frequency of the allelic variants in KIT and AR genes in Mexican population.

\begin{tabular}{|c|c|c|c|c|c|c|c|}
\hline SNV & $\begin{array}{c}\text { Patients with } \\
\text { TGCT and CO } \\
n(\%)\end{array}$ & $\begin{array}{l}\text { Patients with } \\
\text { TGCT } n(\%)\end{array}$ & $\begin{array}{c}P \text { value } \\
\text { TGCT + CO vs } \\
\text { TGCT }\end{array}$ & $\begin{array}{l}\text { Patients with } \\
\text { CO } n(\%)\end{array}$ & $\begin{array}{c}P \text { value } \\
\text { TGCT + CO vs } \\
\text { CO }\end{array}$ & $\begin{array}{c}\text { Healthy } \\
\text { Controls } \boldsymbol{n}(\%)\end{array}$ & $\begin{array}{c}P \text { value } \\
\text { TGCT + CO vs } \\
\text { Control }\end{array}$ \\
\hline \multicolumn{8}{|l|}{ KIT GENE } \\
\hline $\begin{array}{l}\text { D816V (A/T) rs121913507 } \\
\text { c.54733155 }\end{array}$ & $\begin{array}{c}\mathrm{AA}=12(92.3) \\
\mathrm{AT}=1(7.7) \\
\mathrm{TT}=0(0)\end{array}$ & $\begin{array}{c}A A=66(100) \\
A T=0(0) \\
T T=0(0)\end{array}$ & 0.162 & $\begin{array}{c}A A=91(100) \\
A T=0(0) \\
\Pi T=0(0)\end{array}$ & 0.125 & $\begin{array}{c}A A=158(100) \\
A T=0(0) \\
T T=0(0)\end{array}$ & 0.076 \\
\hline $\begin{array}{l}\mathrm{D} 816 \mathrm{H}(\mathrm{G} / \mathrm{C}) \mathrm{rs} 121913506 \\
\mathrm{c.} 54733154\end{array}$ & $\begin{array}{c}\mathrm{GG}=0(0) \\
\mathrm{GC}=11(84.6) \\
\mathrm{CC}=2(15.4)\end{array}$ & $\begin{array}{c}\mathrm{GG}=0(0) \\
\mathrm{GC}=66(100) \\
\mathrm{CC}=0(0)\end{array}$ & 0.025 & $\begin{array}{c}\mathrm{GG}=0(0) \\
\mathrm{GC}=91(100) \\
\mathrm{CC}=0(0)\end{array}$ & 0.015 & $\begin{array}{c}\mathrm{GG}=0(0) \\
\mathrm{GC}=158(100) \\
\mathrm{CC}=0(0)\end{array}$ & 0.005 \\
\hline $\begin{array}{l}\text { N822K (A/T) rs121913514 } \\
\text { c.54733174 }\end{array}$ & $\begin{array}{c}A A=0(0) \\
A T=13(100) \\
T=0(0)\end{array}$ & $\begin{array}{c}A A=0(0) \\
A T=66(100) \\
T T=0(0)\end{array}$ & NA & $\begin{array}{c}\mathrm{AA}=0(0) \\
\mathrm{AT}=89(97.8) \\
\Pi=2(2.2)\end{array}$ & 0.765 & $\begin{array}{c}\mathrm{AA}=0(0) \\
\mathrm{AT}=154(97.5) \\
\mathrm{TT}=4(2.5)\end{array}$ & 0.693 \\
\hline \multicolumn{8}{|l|}{ AR GENE } \\
\hline $\begin{array}{l}\text { Intronic (T/G) rs12014709 } \\
\text { c. } 66718624\end{array}$ & $\begin{array}{c}T \mathrm{~T}=0(0) \\
\mathrm{TG}=13(100) \\
\mathrm{GG}=0(0)\end{array}$ & $\begin{array}{c}T T=2(3.0) \\
T G=63(95.5) \\
G G=1(1.5)\end{array}$ & 0.736 & $\begin{array}{c}\Pi=4(2.5) \\
\mathrm{TG}=80(87.9) \\
\mathrm{GG}=7(7.7)\end{array}$ & 0.415 & $\begin{array}{c}T \mathrm{~T}=4(2.5) \\
\mathrm{TG}=143(90.5) \\
\mathrm{GG}=11(7.0)\end{array}$ & 0.508 \\
\hline $\begin{array}{l}\text { P392S (C/T) rs201934623 } \\
\text { c.67546320 }\end{array}$ & $\begin{array}{c}C C=13(100) \\
C T=0(0) \\
T T=0(0)\end{array}$ & $\begin{array}{c}C C=66(100) \\
C T=0(0) \\
T T=0(0)\end{array}$ & NA & $\begin{array}{c}C C=91(100) \\
C T=0(0) \\
T T=0(0)\end{array}$ & NA & $\begin{array}{c}\mathrm{CC}=158(100) \\
\mathrm{CT}=0(0) \\
T T=0(0)\end{array}$ & NA \\
\hline $\begin{array}{l}\text { A299T (C/T) rs774171864 } \\
\text { c.67546042 }\end{array}$ & $\begin{array}{c}C C=0(0) \\
C T=13(100) \\
\Pi=0(0)\end{array}$ & $\begin{array}{c}C C=0(0) \\
C T=66(100) \\
T T=0(0)\end{array}$ & NA & $\begin{array}{c}C C=0(0) \\
C T=91(100) \\
\Pi=0(0)\end{array}$ & NA & $\begin{array}{c}\mathrm{CC}=0(0) \\
\mathrm{CT}=158(100) \\
T=0(0)\end{array}$ & NA \\
\hline
\end{tabular}

$N A=$ Not Apply. 
TABLE 3 | Clinical features of the patients with TGCT and isolated CO.

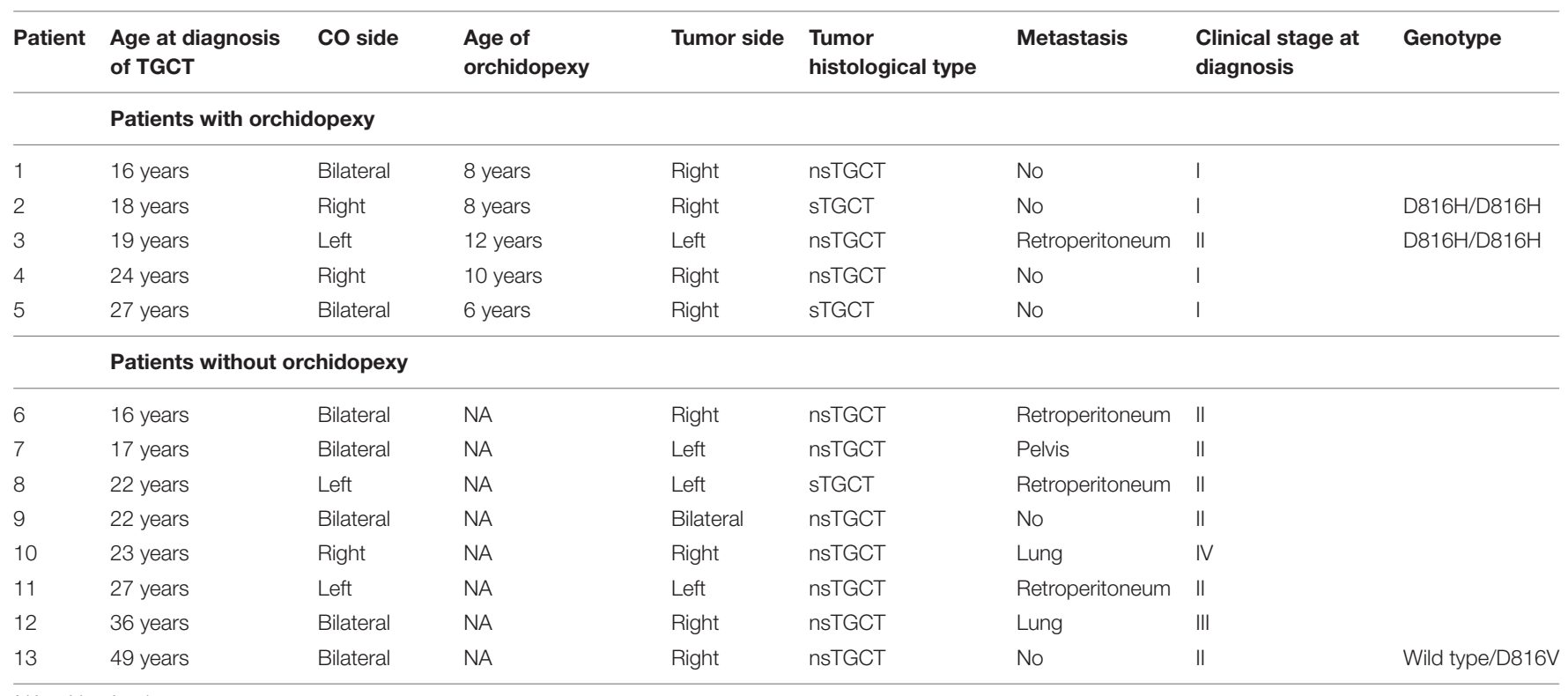

NA $=$ Not Apply.

TABLE 4 | Allelic frequencies of the variables analyzed in the population studied.

\begin{tabular}{|c|c|c|c|c|c|c|c|c|c|c|}
\hline Gene & SNV & Allele & ALL & EUR & AFR & EAS & SAS & AMR & MXL & Mexican \\
\hline & & $\mathrm{T}$ & 0 & 0 & 0 & 0 & 0 & 0 & 0 & 0 \\
\hline & rs121913506 D816H & C & - & - & - & - & - & - & - & 0.50 \\
\hline & \multirow[t]{2}{*}{ rs121913514 N822K } & $A$ & - & - & - & - & - & - & - & 0.49 \\
\hline & & $\mathrm{T}$ & - & - & - & - & - & - & - & 0.51 \\
\hline & rs201934623 P392S & $\mathrm{T}$ & 0.01 & 0 & 0 & 0 & 0.04 & 0 & 0.01 & 0 \\
\hline & \multirow[t]{2}{*}{ rs774171864 A299T } & C & 1 & 1 & 1 & 1 & 1 & 1 & 1 & 0.50 \\
\hline & & $\mathrm{T}$ & 0 & 0 & 0 & 0 & 0 & 0 & 0 & 0.50 \\
\hline & \multirow[t]{2}{*}{ rs12014709 Intronic } & $T$ & 0.85 & 0.91 & 0.58 & 1 & 0.96 & 0.91 & 0.96 & 0.49 \\
\hline & & $G$ & 0.15 & 0.09 & 0.42 & 0 & 0.04 & 0.09 & 0.04 & 0.51 \\
\hline
\end{tabular}

There are no data available on the frequencies of the variant (-), ALL, All gnomeAD, EUR, European Ancestry, AFR, African Ancestry, EAS, East Asian Ancestry, SAS, South Asian Ancestry, AMR, Latino Ancestry, and MXL, Mexican Ancestry in Los Angeles.

fifth place with a mortality rate of 1.3 per 100,000 men (Global Cancer Observatory, 2020). In spite of clinical relationship between $\mathrm{CO}$ and TGCT the molecular mechanisms underlying both diseases are still unknown. Significantly, although the incidence of CO and TGCT has increased worldwide, in Mexico there are few epidemiological data about both diseases.

In this study, we analyzed the clinical manifestations of patients with CO, patients with TGCT and patients with TCGT and history of CO. In the group of patients with CO we found that the incidence of bilateral disease was higher than those reported for Hispanic population [48.3\% (44/91) vs 19.7\% (25/127)] (Davis-Dao et al., 2012). However, other findings were similar to other studies. Surgical intervention in $70 \%$ of the patients with $\mathrm{CO}$ done after 2 years (Williams et al., 2018) compared with $73.6 \%$ in our study, and the family history of TGCT in our patients with $\mathrm{CO}$ and in
Italian population $[2.2 \%(2 / 91)$ vs $2.1 \%$ (15/721; Foresta et al., 2008)] (Table 1).

In addition, in the group of TGCT patients we did not find $\mathrm{CO}$ history, compared to other reports who found $\mathrm{CO}$ history in $5-10 \%$ (Kratz et al., 2010) and 14.6\% (18/123) of TGCT patients (Garolla et al., 2005). On the other hand, we identify $4.5 \%$ patients with TGCT without $\mathrm{CO}(3 / 66)$ with at least one family member affected by the same neoplasm, and a global frequency of $3.8 \%$ (3/79 patients with TGCT), these were according to other authors for familiar TGCT (Mai et al., 2009; Rapley and Nathanson, 2010); we also observed higher frequency of nsTGCT in our patients with TGCT, similar to Hispanic population (Woldu et al., 2018; Table 1).

$\mathrm{CO}$ is an important risk factor for the development of TGCT, and this relationship has been clinically established, however, the molecular mechanism between failure in 
testicular descent and the development of malignancy, is still unknown (Ferguson and Agoulnik, 2013). Several genes have been associated to the development of TGCT (Rapley and Nathanson, 2010; Landero-Huerta et al., 2017), but only a few of them, such as KIT gene expression (ViguerasVillaseñor et al., 2015), or polyQ inserts in exon 1 of the $A R$ gene (Ferlin et al., 2005; Davis-Dao et al., 2011; Hutson et al., 2015; Fukawa and Kanayama, 2018) have been analyzed in patients with $\mathrm{CO}$, without establish a relationship between CO and TGCT.

Therefore, we focused on determine the relationship between 6 SNVs in both KIT and $A R$ genes and TGCT and CO in Mexican population. The contrast of the patients with TGCT and history of CO with TGCT without CO, or those with CO as well as control group showed statistical differences in the presence of the homozygous form (CC) of the rs121913506 $(\mathrm{D} 816 \mathrm{H})$ variant of the KIT gene in two patients with TGCT and history of $\mathrm{CO}$, these results suggested that $\mathrm{CO}$ patients with $\mathrm{C}$ allele in homozygous form might have a higher risk of development TGCT. The frequency of $\mathrm{C}$ allele in homozygous form in our group of TGCT Mexican patients was similar to the reported in Japanese population (Sakuma et al., 2003) [2.5\% (2/79) vs 2.9\% (1/34)]. Although the other SNVs did not show statistical differences, we consider pertinent not to discard them as important SNVs in Mexican population, therefore, these results must be explored in higher number of samples. In previous reports, the rs121913506 (D816H) variant has been considered as mutation related to TGCT (Looijenga et al., 2003), however, we identified the same variant in heterozygous form in the majority of patients and even in the control group, therefore our population could have a different genotype.

In the group of patients with TGCT, we considered the simultaneous presence of TGCT and CO as the most important factor, so we analyzed individually this subgroup of 13 patients, and we found that the variants rs121913507 (D816V) and rs121913506 $(\mathrm{D} 816 \mathrm{H})$ of the KIT gene were identified in 3 patients (2, 3, and 13 patients; Table 3); however, there were not association between these genetic variants and any particular phenotype or clinical feature. However, the results obtained from the clinical characteristics indicated that the patients with TGCT with previous CO could express a more aggressive phenotype of the TGCT, which itself is already severe (Table 3 ). These results suggest that the relationship between $\mathrm{CO}$ and severe TGCT phenotypes could be due to the participation of the function of multiple genes and not exclusively by KIT and $A R$. In particular, we observed that patients who did not undergo orchidopexy at right time had a more severe TGCT phenotype (Table 3 ). We could highlight the importance of performing orchidopexy in a timely manner, minimizing the risk and complications in the pediatric patient with CO (Table 3), and avoiding undescended testes to be subject to different abnormal stress conditions (Williams et al., 2018).

Additionally, the comparison of the allelic frequencies for the rs121913506 (D816H) and rs121913514 (N822K) variants in other populations was not possible due to lack of available information in the HapMap and in the project of the 1000 genomes. However, the frequencies for the allele $\mathrm{A}$ of the variant rs121913507 (D816V) in the KIT gene, and for the allele $\mathrm{C}$ of the variant rs201934623 (P392S) in the $A R$ gene, were similar to that found in all populations. In the case of the both alleles of the variant rs774171864 (A299T), the frequencies were different to all databases, and the allelic frequencies of the variant rs12014709 were similar only with the AFR. Finally, we identified a mixed population in population structure analysis, according to previously reports for Mexican population with predominantly Amerindian and EUR (Salazar-Flores et al., 2015).

In conclusion, the results of this study support the fact that $\mathrm{CO}$ is a risk factor for the development of TGCT at molecular level. KIT gene variants rs121913507 and rs121913506 might be common among TGCT and CO. However, more studies must perform to clarify these results and to find predictive biomarkers for TGCT and $\mathrm{CO}$ patients.

\section{DATA AVAILABILITY STATEMENT}

The raw data supporting the conclusions of this article will be made available by the authors, without undue reservation, to any qualified researcher.

\section{ETHICS STATEMENT}

The studies involving human participants were reviewed and approved by the project with registration number INP-01/2016, approved by the Research and Ethics Committee of INP. Written informed consent to participate in this study was provided by the participants' legal guardian/next of kin.

\section{AUTHOR CONTRIBUTIONS}

MC-S contributed to conception and design. DL-H, MC$\mathrm{S}, \mathrm{FG}-\mathrm{A}$, and JR-C contributed to the development of the methodology. MC-S, RV-V, EY-R, IP-A, and EA-O performed the analysis and interpreted the data. DL-H, MC-S, and RV-V contributed to writing, review, and revision of the manuscript. LH-M, JD-C, and JR-C provided administrative, technical, or material support. RV-V, MC-S, and DL-H contributed to study supervision. All authors contributed to the article and approved the submitted version.

\section{FUNDING}

The authors thank CONACyT for financial support CONACyT FOSISS (Project 272641/2017) and Instituto Nacional de Pediatría INP: 01/2016. CONACyT for the scholarship granted to DL-H (No. 429258), DL-H submitted this article to fulfill the graduate requirement for a $\mathrm{Ph}$.D. degree at Posgrado en Ciencias Naturales e Ingeniería of Universidad Autónoma Metropolitana Unidad Cuajimalpa. 


\section{REFERENCES}

Agarwal, S., Kazi, J., Mohlin, S., Påhlman, S., and Rönnstrand, L. (2014). The activation loop tyrosine 823 is essential for the transforming capacity of the c-Kit oncogenic mutant D816V. Oncogene 34, 4581-4590. doi: 10.1038/onc. 2014.383

Banks, K., Tuazon, E., Berhane, K., Koh, C., De Filippo, R., Chang, A., et al. (2013). Cryptorchidism and testicular germ cell tumors: comprehensive meta-analysis reveals that association between these conditions diminished over time and is modified by clinical characteristics. Front. Endocrinol. 3:182. doi: 10.3389/ fendo.2012.00182

Barrett, J., Fry, B., Maller, J., and Daly, M. (2004). Haploview: analysis and visualization of LD and haplotype maps. Bioinformatics 21, 263-265. doi: 10. 1093/bioinformatics/bth457

Berney, D., Looijenga, L., Idrees, M., Oosterhuis, J., Rajpert-De Meyts, E., Ulbright, T., et al. (2016). Germ cell neoplasiain situ(GCNIS): evolution of the current nomenclature for testicular pre-invasive germ cell malignancy. Histopathology 69, 7-10. doi: 10.1111/his. 12958

Dalgaard, M., Weinhold, N., Edsgärd, D., Silver, J., Pers, T., Nielsen, J., et al. (2011). A genome-wide association study of men with symptoms of testicular dysgenesis syndrome and its network biology interpretation. J. Med. Genet. 49, 58-65. doi: 10.1136/jmedgenet-2011-100174

Davis-Dao, C., Koh, C., Hardy, B., Chang, A., Kim, S., De Filippo, R., et al. (2012). Shorter androgen receptor CAG Repeat lengths associated with cryptorchidism risk among hispanic white boys. J. Clin. Endocrinol. Metab. 97, E393-E399. doi: 10.1210/jc.2011-2439

Davis-Dao, C., Siegmund, K., Vandenberg, D., Skinner, E., Coetzee, G., Thomas, D., et al. (2011). Heterogenous effect of androgen receptor CAG tract length on testicular germ cell tumor risk: shorter repeats associated with seminoma but not other histologic types. Carcinogenesis 32, 1238-1243. doi: 10.1093/carcin/ bgr104

Dieckmann, K., and Pichlmeier, U. (2004). Clinical epidemiology of testicular germ cell tumors. World J. Urol. 22, 2-14. doi: 10.1007/s00345-004-0398-8

Ferguson, L., and Agoulnik, A. (2013). Testicular cancer and cryptorchidism. Front. Endocrinol. 4:32. doi: 10.3389/fendo.2013.00032

Ferlin, A., Garolla, A., Bettella, A., Bartoloni, L., Vinanzi, C., Roverato, A., et al. (2005). Androgen receptor gene CAG and GGC repeat lengths in cryptorchidism. Eur. J. Endocrinol. 152, 419-425. doi: 10.1530/eje.1.01860

Foresta, C., Zuccarello, D., Garolla, A., and Ferlin, A. (2008). Role of hormones, genes, and environment in human cryptorchidism. Endoc. Rev. 29, 560-580. doi: 10.1210/er.2007-0042

Fukawa, T., and Kanayama, H. (2018). Current knowledge of risk factors for testicular germ cell tumors. Int. J. Urol. 25, 337-344. doi: 10.1111/iju.13519

Garolla, A., Ferlin, A., Vinanzi, C., Roverato, A., Sotti, G., Artibani, W., et al. (2005). Molecular analysis of the androgen receptor gene in testicular cancer. Endocr. Relat. Cancer 12, 645-655. doi: 10.1677/erc.1.00954

Global Cancer Observatory (2020). Globocan.iarc.fr. 2020. Available from: http: //globocan.iarc.fr/(accessed April, 22 2020).

Hutson, J., Li, R., Southwell, B., Newgreen, D., and Cousinery, M. (2015). Regulation of testicular descent. Pediatr. Surg. Intl. 31, 317-325. doi: 10.1007/ s00383-015-3673-4

Kratz, C., Mai, P., and Greene, M. (2010). Familial testicular germ cell tumours. Best. Pract. Res. Clin. Endocrinol. Metab. 24, 503-513. doi: 10.1016/j.beem.2010. 01.005

Landero-Huerta, D. A., Vigueras-Villaseñor, R. M., Yokoyama-Rebollar, E., Aréchaga-Ocampo, E., Rojas-Castañeda, J. C., et al. (2017). Epigenetic and risk factors of testicular germ cell tumors: a brief review. Front. Biosci. 22:1073-1098. doi: $10.2741 / 4534$

Li, J., and Al-Azzawi, F. (2009). Mechanism of androgen receptor action. Maturitas 63, 142-148. doi: 10.1016/j.maturitas.2009.03.008

Litchfield, K., Levy, M., Orlando, G., Loveday, C., Law, P., Migliorini, G., et al. (2017). Identification of 19 new risk loci and potential regulatory mechanisms influencing susceptibility to testicular germ cell tumor. Nat. Genet. 49, 11331140. doi: $10.1038 /$ ng.3896

Looijenga, L., Leeuw, H., Oorschot, M., Gurp, R., Stoop, H., Gillis, A., et al. (2003). Stem cell factor receptor (c-KIT) codon 816 mutations predict development of bilateral testicular germ-cell tumors. Cancer Res 63, 7674-7678.23.

Mai, P., Chen, B., Tucker, K., Friedlander, M., Phillips, K., Hogg, D., et al. (2009). Younger age-at-diagnosis for familial malignant testicular germ cell tumor. Fam. Cancer 8, 451-456. doi: 10.1111/andr.293

Merlet, J., Racine, C., Moreau, E., Moreno, S., and Habert, R. (2007). Male fetal germ cells are targets for androgens that physiologically inhibit their proliferation. Proc. Natl. Acad. Sci. U.S.A. 104, 3615-3620. doi: 10.1073/pnas. 0611421104

Moore, J., Gilbert, J., Tsai, C., Chiang, F., Holden, T., Barney, N., et al. (2006). A flexible computational framework for detecting, characterizing, and interpreting statistical patterns of epistasis in genetic studies of human disease susceptibility. J. Theor. Biol. 241, 252-261. doi: 10.1016/j.jtbi.2005.11.036

Rapley, E., and Nathanson, K. (2010). Predisposition alleles for testicular germ cell tumour. Curr. Opin. Genet. Dev. 20, 225-230. doi: 10.1016/j.gde.2010.02.006

Rosenberg, N. (2002). Genetic structure of human populations. Science 298, 23812385. doi: 10.1126/science.1078311

Sakuma, Y., Sakurai, S., Oguni, S., Hironaka, M., and Salto, K. (2003). Alterations of the c-kit gene in testicular germ cell tumors. Cancer Sci. 94, 486-491. doi: 10.1111/j.1349-7006.2003.tb01470.x

Salazar-Flores, J., Zuñiga-Chiquette, F., Rubi-Castellanos, R., Álvarez-Miranda, J., Zetina-Hérnandez, A., Martínez-Sevilla, V., et al. (2015). Admixture and genetic relationships of mexican mestizos regarding latin american and caribbean populations based on 13 CODIS-STRs. Homo 66, 44-59. doi: 10.1016/j.jchb. 2014.08.005

Sheikine, Y., Genega, E., Melamed, J., Lee, P., Reuter, V., and Ye, H. (2012). Molecular genetics of testicular germ cell tumors. Am. J. Cancer Res. 2, 153-167.

Trabert, B., Chen, J., Devesa, S., Bray, F., and McGlynn, K. (2014). International patterns and trends in testicular cancer incidence, overall and by histologic subtype, 1973-2007. Andrology 3, 4-12.

Turnbull, C., and Rahman, N. (2011). Genome-wide association studies provide new insights into the genetic basis of testicular germ-cell tumour. Int. J. Androl. 34, e86-e97. doi: 10.1111/j.1365-2605.2011.01162.x

Vigueras-Villaseñor, R., Cortés-Trujillo, L., Chávez-Saldaña, M., Vázquez, F., Carrasco-Daza, D., Cuevas-Alpuche, O., et al. (2015). Analysis of POU5F1, c-Kit, PLAP, AP $2 \gamma$ and SALL4 in gonocytes of patients with cryptorchidism. Acta Histochem. 117, 752-761. doi: 10.1016/j.acthis.2015.08.004

Walker, W. (2003). Nongenomic actions of androgen in sertoli cells. Curr. Top. Dev. Biol. 56, 25-53. doi: 10.1016/s0070-2153(03)01006-8

Williams, K., Baumann, L., Shah, A., Abdullah, F., Johnson, E., and Oyetunji, T. (2018). Age at orchiopexy for undescended testis in the United States. J. Pediatr. Surg. 53, 86-89. doi: 10.1016/j.jpedsurg.2017.10.020

Woldu, S., Aydin, A., Rao, A., Hutchinson, R., Singla, N., Clinton, T., et al. (2018). Differences at presentation and treatment of testicular cancer in hispanic men: institutional and national hospital-based analyses. Urology 112, 103-111. doi: 10.1016/j.urology.2017.08.059

Conflict of Interest: The authors declare that the research was conducted in the absence of any commercial or financial relationships that could be construed as a potential conflict of interest.

Copyright (C) 2020 Landero-Huerta, Vigueras-Villaseñor, Yokoyama-Rebollar, García-Andrade, Rojas-Castañeda, Herrera-Montalvo, Díaz-Chávez, Pérez-Añorve, Aréchaga-Ocampo and Chávez-Saldaña. This is an open-access article distributed under the terms of the Creative Commons Attribution License (CC BY). The use, distribution or reproduction in other forums is permitted, provided the original author(s) and the copyright owner(s) are credited and that the original publication in this journal is cited, in accordance with accepted academic practice. No use, distribution or reproduction is permitted which does not comply with these terms. 